\title{
Article
}

\section{Making mentoring work: The need for rewiring epistemology}

Olsson, C., Cruickshank, A., and Collins, D.

Available at http://clok.uclan.ac.uk/12778/

Olsson, C. ORCID: 0000-0002-8418-5190, Cruickshank, A., ORCID: 0000-00028893-2341 and Collins, D. ORCID: 0000-0002-7601-0454 (2017) Making mentoring work: The need for rewiring epistemology. Quest, 69 (1). pp. 50-64. ISSN 0033-6297

It is advisable to refer to the publisher's version if you intend to cite from the work. http://dx.doi.org/10.1080/00336297.2016.1152194

For more information about UCLan's research in this area go to http://www.uclan.ac.uk/researchgroups/ and search for < name of research Group>.

For information about Research generally at UCLan please go to http://www.uclan.ac.uk/research/

All outputs in CLoK are protected by Intellectual Property Rights law, including Copyright law. Copyright, IPR and Moral Rights for the works on this site are retained by the individual authors and/or other copyright owners. Terms and conditions for use of this material are defined in the policies page.

\section{CLoK}

Central Lancashire online Knowledge www.clok.uclan.ac.uk

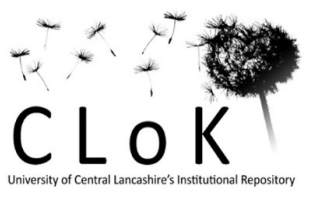


This is a pre-proof corrected manuscript, as accepted for publication, of an article published by Taylor \& Francis in Quest on $28^{\text {th }}$ April 2016, available online at: http://www.tandfonline.com/doi/full/10.1080/00336297.2016.1152194

\section{Making Mentoring Work: The Need for Rewiring Epistemology}

Cliff Olsson, Andrew Cruickshank and Dave Collins

School of Sport \& Wellbeing / Institute of Coaching and Performance

University of Central Lancashire 


\begin{abstract}
To help produce more expert coaches at both participation and performance levels, a number of governing bodies have established coach mentoring systems. In light of this trend, against the limited literature on coach mentoring and the risks of superficial treatment by coach education systems, this paper critically discusses the role of the mentor in coach development, the nature of the mentor-mentee relationship and, most specifically, how expertise in the mentee may best be developed. If mentors are to be effective in developing expert coaches, we consequently argue that a focus on personal epistemology is required. On this basis, we present a framework that conceptualizes mentee development on this level through a step by step progression, rather than through an unrealistic and unachievable leap toward expertise. Finally, we consider the resulting implications for practice and research with respect to one-on-one mentoring, communities of practice, and formal coach education.
\end{abstract}




\section{Making Mentoring Work: The Need for Rewiring Epistemology}

Defining and developing expert coaching has long been a focus for researchers and practitioners. To help produce more expert coaches at both participation and performance levels, a number of governing bodies (e.g., the English Football Association) have established coach mentoring systems. However, although this approach is well-justified (Nash, 2003), the underpinning theory and mechanisms by which mentors can develop mentee expertise are poorly understood. Accordingly, as mentors will invariably possess a more complex view of knowledge, learning and practice than their mentees, mentoring is likely to be suboptimal at best - and doomed to fail at worst - unless critical consideration is given to the precise goal, nature, and process of this relationship. Consequently, this paper critically discusses the role of the mentor in coach development, the nature of the mentor-mentee relationship, and, most specifically, how mentee expertise may best be developed.

To achieve our goal and stimulate interest in an understudied area (cf. Jones, Harris, $\&$ Miles, 2009), our paper is structured in four main parts. To frame our whole discussion, we firstly define the expert coach; in short, the type of coach that mentors are being tasked to develop (or develop as far as possible). Building on this definition, we then consider the limits of many current coach education systems for developing expertise. Thirdly, we consider the potential role of mentoring in addressing these issues and present a framework grounded in personal epistemology - that can conceptualize the development of expertise in mentee coaches. Finally, we consider some consequent implications for the applied mentoring process, which also provide a frame for future research (cf. Giacobbi, Poczwardowski, \& Hager, 2005).

\section{Defining the Expert Coach}

Responding to early definitions of expertise that revolved around coaching behaviors, Nash, Martindale, Collins, and Martindale (2012) recently proposed a set of cognitive-based 
criteria against which expertise can be more accurately classified. Essential components included: use of a large declarative knowledge base to solve problems and make decisions; use of perceptual skills, mental models, and routines; an ability to work independently and develop innovative solutions; use of effective reflection, experimentation, and lifelong learning; an awareness of personal strengths and limits; and management of complex planning processes. Noticeably, a track record of developing performers from one stage to another (e.g., development to world class level) was defined as a possible marker of coach expertise. Notably, the criteria proposed by Nash et al. (2012) define expertise across all coaching domains, covering the full participation-to-performance spectrum. Indeed, while there is much variation in how expertise is played out on a behavioral level (even within the same domain), its' cognitive underpinnings, by definition, are consistent.

In sum, expert coaching involves much more than applying "solution $\mathrm{X}$ to problem Y”, even if the solution has worked before. Instead, the expert coach is able to recognize the most relevant information in multi-faceted situations to help their athletes/teams to optimally develop or perform in their ever-evolving contexts (Nash et al., 2012). For example, a soccer coach who is just starting on their journey towards expertise may recognize that players are not passing effectively and then attempt to solve this with training practices that focus on passing technique. In contrast, a coach with established expertise might have recognized that this problem was symptomatic of poor conceptual understanding of support play and thus design sessions that foster development in this area in line with other "nested" development needs (cf. Abraham \& Collins, 2011). Some may argue that such insight is an art, rooted in a "natural flair" for coaching (or tacit knowledge of this art) that is acquired automatically through time on the job. In contrast, however, it is now well-established in the literature that coaching expertise can (and should) be intentionally developed (Collins, Burke, Martindale, 
\& Cruickshank, 2015). Indeed, "coaching is not behavior to be copied but a cognitive skill to be taught" (Abraham \& Collins, 1998).

\section{Developing the Expert Coach: Limitations of Training-Based Approaches}

Considering how coaches accrue knowledge and develop expertise, Werthner and Trudel (2006) identified three avenues of learning: mediated learning, unmediated learning, and internal learning. Mediated learning is externally driven and includes activities such as formal education courses; unmediated learning relates to areas such as feedback from more experienced peers or mentors; and internal learning occurs when a coach critically reflects on their current practice (Wiman, Salmoni, \& Hall, 2010). As the primary education vehicle in most sports systems, we focus here on mediated learning and the limitations of formal coach education in developing and sustaining expert coaches (please note that we address unmediated and internal learning in the following sections on mentoring).

Despite the cognitive basis of expertise, many coaching courses still reinforce images of coaches as behavioral technicians (Cushion, Armour, \& Jones 2003). Indeed, the coaching process is often broken down into specific and isolated competencies that reflect "best practice" but yet have little theoretical or empirical basis for developing higher level expertise (Cushion, 2003; Collins et al., 2015). In these systems, coaches are primarily trained on the acquisition and demonstration of certain behaviors and rigid decision making processes; normally influenced by the system's desire for uniformity and consistency in coaching standards. Although novice coaches may initially benefit from tight frameworks as foundational knowledge is accrued, the continuation of this "copy and paste" thread in higher-level awards unfortunately reflects a process of indoctrination rather than education (Cushion, 2010).

Thus, against the expertise criteria listed earlier, the reality for many coaches is that formal coach education does not, therefore, adequately prepare them to manage the diverse 
range of environments, challenges, and pressures that they will face in practice (Cushion, Armour, \& Jones, 2003). With many programs still delivered in isolated and irrelevant contexts, including a focus on drills and behaviors rather than thinking structures and patterns, such "neat and tidy" courses are at odds with the complex and dynamic setting in which coaches are required to operate; in effect, there is an "epistemological mismatch".

\section{Coach Mentoring: A Route for Impact?}

Based perhaps on the accepted limits of "one-off” or isolated education courses (cf. Nelson, Cushion, \& Potrac, 2013), as well as the recognized benefits of interacting with experienced practitioners (Cushion 2003; Wiman et al., 2010), a number of sports have introduced mentoring as a way to better develop creative, forward-thinking, and adaptable coaches; or, in other words we suggest, those which reflect the expertise criteria listed earlier in this paper. While there is no single definition of mentoring (Cassidy, Jones, \& Potrac, 2004), emphasis is often placed on the provision of guidance and support (Bloom, DurandBush, Schinke, \& Salmela, 1998; Parsloe \& Wray, 2000). More specifically, mentoring is often portrayed as a process of listening, questioning, and facilitating; as distinct from telling, restricting, and directing (Jones et al., 2009; Roberts, 2000). By its nature, mentoring is therefore viewed against the responsibilities, challenges, and goals of each individual coach and something that is done with rather than to mentees (Jones et al., 2009).

Of course, the type of knowledge that is targeted for development and the steps taken to reach higher-level thinking are vital to the nature and extent of expertise that is ultimately developed. Certainly, while unfocused mentoring has the potential to develop expert coaches, failure to consider the theory and mechanisms of this process will likely amplify a training approach to coach development and exacerbate the problems of "copy and paste" coaching. For example, Cushion (2003) has already criticized unstructured and uncritical approaches to mentoring for simply reinforcing the "learn-drill-do" orthodoxy and producing 
"souped up versions of the same" (p. 216). In short, if mentors view coaching knowledge as concrete, owned by higher authorities, and easily measured by simple and isolated competencies - as is often suggested by formal coach education - then there is a clear danger that mentoring simply reinforces what sports already have. In this way, past playing experience and/or a breadth of technical knowledge alone will not make an individual an expert (or perhaps even competent) mentor. Rather, if the aim of mentoring is to develop expert coaches, then mentors need to possess a deep understating of how mentees approach, acquire, develop, and use coaching knowledge. In short, cognitive excellence is impossible without excellent knowledge on how it is best acquired!

\section{Personal Epistemology: A Foundation for Effective Mentoring}

Given the importance of understanding "how knowledge works", we suggest that it is crucial for mentors to therefore consider the role of personal epistemology for their practice. Epistemological beliefs relate to the nature and scope of knowledge, including how it can be acquired and what is and can be "known". These beliefs are fundamental to how individuals engage with learning and teaching. Treating personal epistemology as a multi-dimensional construct, Schommer-Aikins and Easter (2009) argued that five beliefs underpin the acquisition, development, and use of knowledge. More specifically, these relate to the extent to which knowledge is viewed as (a) simple and isolated facts or complex interwoven concepts, (b) stable and certain or tentative and changing, (c) handed down by omniscient authorities or developed through personal reasoning and evidence, (d) learned quickly/not at all or gradually/recursively, and (e) limited by the learner's fixed capacity or subject to continuous development. Importantly, Schommer-Aikins and Easter argued that these beliefs are independent of each other and do not all have to be at the same level. For example, a person may believe that knowledge on a particular issue/topic is structured in complex interrelationships (as per belief "a" above) yet, at the same time, only source and use 
solutions provided by perceived authorities (as per belief "c" above) (cf. Schommer-Aikins, Brookhart, Hutter, \& Wei Cheng, 2000).

While it might be attractive to label learners along an epistemological continuum (i.e., coach $\mathrm{X}$ is naïve, coach $\mathrm{Y}$ sophisticated, and coach $\mathrm{Z}$ somewhere in the middle), SchommerAikins and Hutter (2002) argued that one's epistemology is best characterized as a distribution. In this way, a naïve individual may believe that $75 \%$ of knowledge is certain, $15 \%$ to be discovered, and $10 \%$ evolving. At the same time, they might also believe that $80 \%$ of learning happens immediately with only $20 \%$ happening over a sustained period of time. A more sophisticated individual, on the other hand, may believe that $10 \%$ of knowledge is certain, $20 \%$ is yet to be discovered, and $70 \%$ is evolving while also believing that $80 \%$ of learning occurs gradually with only $20 \%$ done immediately. In sum, the more that a coach believes that knowledge is complex and tentative, derived from reason, constantly evolving and developed over a long time, then the more likely they are to be critically reflective, adaptive, and creative in their thinking (Schommer-Aikins \& Hutter, 2002). More sophisticated beliefs will also increase the likelihood of individuals appropriately questioning and challenging knowledge that is held and shared by others; a vital feature for avoiding the copy and paste coaching mentioned earlier, especially when "expert opinion" is incessantly spewed out from television programs, radio shows, websites, blogs, and Twitter feeds (Nussbaum \& Bendixen, 2003; MacNamara \& Collins, 2015)

Importantly, evaluation of the role of personal epistemology in coaching practice has recently become a focus for researchers. Grecic and Collins (2013) have argued that coaches would have greater role clarity, functional understanding, and developmental potential if they proactively and regularly engaged with their epistemology (i.e, their core beliefs on the origins, constructions, and use of coaching knowledge). As most cognition and behavior is driven by, or shaped through our core beliefs and values (Nash, Sproule, \& Horton, 2008), 
Grecic and Collins noted that such understanding can help coaches to frame their decision making, overall practice, and how they pursue, construct, and evaluate new learning experiences. In other words, a coach's epistemology can be used as a critical sieve to plan and evaluate all aspects of coaching practice and development (Stoszkowski \& Collins 2014). Indeed, Grecic and Collins (2013) have demonstrated how a coach's epistemological position is reflected in the environment that they create, methods used, behaviors employed, relationships built, goals set and the decisions made with regards to performer development. For example, a more naïve coach will generally work in an autocratic fashion, foster obedient performers who learn by following prescribed rules, and gauge success against simple results (e.g., win/loss record). In this case, the performer will be highly dependent on the coach and develop limited levels of adaptability, independence, and resilience (cf. Blind Reference A, 2015). By contrast, a more sophisticated coach will generally empower their performers, encourage experimentation, set goals and evaluate progress collaboratively, and generate an environment where questioning and challenge, as underpinned by mutual respect and trust, is the norm. In this case, coaches therefore help to develop adaptive, independent, and resilient performers (which seems to be the main goal of most development systems; cf. Blind Reference A, 2015).

Significantly, however, coaches with more sophisticated epistemologies might not be the most effective for performer development in all situations. Certainly, there may be times where a more naïve coach is more suited to a particular job (e.g., to provide clear direction to performers who need a "do it like this" approach at a particular point of their development). However, if sports wish to develop adaptable, independent and resilient performers, who can meet the shifting demands of their sport, then a substantial body of sophisticated coaches who can support this goal is needed (Collins, Abraham, \& Collins 2012). In short, if sports want 
expert/sophisticated performers then mentors need to logically develop expert/sophisticated mentee coaches.

\section{Optimizing the Mentoring Process: A Guiding Framework}

Taking mentee epistemology as a logical focus for developing sophisticated coaches, what sort of approach might mentors consequently adopt? To answer this question, we turn to a framework presented by Entwistle and Peterson (2004) on adult knowledge and learning within higher education (see Figure 1). Integrating the work of Perry (1970) and SchommerAikins (2002), Entwistle and Peterson's framework outlines stages of progression along two continua; the individual's conceptions of knowledge (emanating from epistemology) and their conceptions of learning (emanating from constructivism and cognitive psychology). As per the upper continuum in Figure 1, conceptions of knowledge are anchored by a dualistic and factual (or "black and white") standpoint at one end to a relativistic and reasoned (or "shades of grey") standpoint at the other. Resonating with Schommer-Aikins and Easter's (2009) views on naïve epistemologies, those with a dualist conception of knowledge will see coaching as based on clearly prescribed "facts" and heuristics with little need for (or awareness of) interpretation and creativity. This is in stark contrast to the relativist coach (with a sophisticated epistemology: Schommer-Aikins) who would see knowledge as tentative, open to interpretation, and used to support creative and adaptive actions. Between these anchors are individuals who initially see that there can be multiple and equally valuable views on a topic and that knowledge is provisional rather that concrete (multiplism). This is then followed by a pivotal advance (see dashed line in Figure 1) where relativism is acknowledged and individuals then begin to use evidence to debate the "pros and cons" of different perspectives, culminating in the development of a personal and informed perspective. 
In terms of an individual's conceptions of learning, Entwistle and Peterson's (2004) framework details that learners, or mentee coaches in our case, begin with rote learning and reproduction based on external sources that set the benchmark of "correctness" by providing the "right" answers. Coach learning is therefore oriented towards listening to and following coach educators and more advanced/respected peers, as well as other influential sources such as television pundits and current and former performers; all of whom possess varying levels of actual expertise and target their messages for varying purposes and audiences. From this starting point, coaches then move to apply what they have learned by consistently thinking and reflecting on their learning. Similar to the conceptions of knowledge, once individuals start to develop a deep understanding of what they have learned a threshold is reached where emphasis then shifts from thinking and reflecting to searching for/establishing meaning and seeing things in ways that were previously inaccessible.

In pursuit of coaches who are committed to a personal, evidence-based, adaptive, and creative approach, Entwistle and Peterson's (2004) framework suggests that mentors should therefore help mentees to make a "step by step" progression - rather than an unrealistic and unachievable "leap" - toward relativism and sophistication. In this manner, overlap is found with Vygotsky's (1978) zone of proximal development where learners are supported to move beyond what they are currently able to do through help from, or collaboration with a more capable other. Of course, having to abandon long-held beliefs, assumptions, and "facts" will be a substantial, taxing, and uncomfortable journey for the mentee (and, perhaps, the mentor), including inevitable dips in confidence and, potentially, performance. As a result, many will shy away from the apparently reduced clarity and "right or wrongs" of sophistication, remain reluctant to update their beliefs, ignore contrary evidence (especially when it challenges the authority of influential figures), and stay within or return to the dualist comfort zone of "hard and fast facts" (Schempp, McCullick, \& Sannen Mason, 2006; Tetlock, 2005). Indeed, Perry 
(1970) stated that individuals can be at different positions for different amounts of time during their development, as well as halting or reversing their growth at any point; progress is neither uniform nor continuous. Accordingly, the mentee's journey from "learn-drill-do" to "it all depends" requires significant care and treatment from their mentor, together with an acceptance, or even commitment from the mentee, to making the journey.

\section{Rewiring Coach Epistemologies: Implications for Practice and a Frame for Research}

Building on our presented messages, we now consider some general mechanisms that may help mentee coaches develop a relativist view of knowledge and pursue meaning in their learning. As key provisos, we must clarify that our focus is on how mentors may best help their mentees work towards expertise by rewiring their epistemology; regardless of whether that mentee operates in a participation or performance role. Second, mentors will of course need a thorough understanding of what expertise is (and isn't) plus the theory of developing on an epistemological-level; something that, as far as we are aware, would be a major change in many sports' mentor selection policies. Indeed, there would appear little hope for mentors (if expertise is desired) should their mentee subscribe to the competency-based, learn-drill-do orthodoxy mentioned earlier. Finally, we recognize that not all mentees will, initially at least, have the skills, support, or desire to complete the journey to full sophistication/higher-level expertise. These individuals can still, of course, be highly effective when a commitment to "keeping it simple" is needed (Collins et al., 2012); provided that they, alongside sophisticated/expert coaches, appreciate their limits. However, as mentors are being asked to help develop more expert coaches, we now consider various routes by which the rewiring process might operate. More specifically, we cover exemplar micro (i.e., one-on-one mentoring), meso (i.e., social) and macro (i.e., coach education) factors that may support mentors in their work. We also hope that his provides a useful frame for future research (cf. Giacobbi et al., 2005). 


\section{Micro-Level Action: One-on-One Mentoring}

As a logical first step, it is clearly important that mentors and their mentees define and map out the long-term objectives of their working relationship. Through this, the mentor will sensibly identify the mentee's ultimate aims (e.g., to develop into a forward-thinking, creative lead coach) and preferences on the nature of their relationship moving ahead (cf. Martindale \& Collins, 2005). As part of this groundwork, it would also seem sensible for the mentee to provide a general overview of what eventual expertise would look like (i.e., having the ability to work independently and innovatively with complex challenges), what the journey is likely to involve (i.e., an increasing awareness and consideration of multiple ways to solve coaching challenges), and what the journey is also likely to feel like (i.e., consistently working outside of one's comfort zone mixed with blocks of consolidation). Of course, the language used at this stage will be vital; detailed enough to set expectations but simple enough so that mentees are not immediately intimidated or disillusioned. Accordingly, "epistemology" might not be mentioned in most first meetings! Notwithstanding this point, however, it will still be crucial for a mentor to quickly gain an understanding of the mentee's current epistemological distribution. Part of a broader "getting to know each other" block, where trust and rapport are also targeted, this epistemological evaluation will sensibly involve the triangulation of data from sources such as informal discussions, observations of practice, and perceptions of peers/seniors. Using Schommer-Aikins and Easter's (2009) five epistemological beliefs as a guide, mentors will need to consider this data with respect to the mentee's views on the origins, stability, certainty, organization, acquisition, and learnability of knowledge. Once again, it will be important to explain to the mentee why these types of conversations and observations are taking place, but not necessarily in overt "epistemological terms". Indeed, the extent to which technical language is used and progressed will of course depend upon 
each individual (as such, we do not prescribe any concrete guidelines on when and how "personal epistemology" should be directly referred to).

From here, early mentoring with naïve mentees will then focus on developing a broad base of declarative knowledge, focused on the techniques and tactics of their sport (including the provision of drills that can be simply copied at this stage - although increasingly with alternatives included), pedagogical principles, basic tenets of major support disciplines (e.g., skill development; sport psychology), and the social and political features of their work (Abraham, Collins, \& Martindale, 2006; Potrac \& Jones, 2009). Given the mentee's likely preference to acquire, memorize, and reproduce fact-based information at this stage, this knowledge will be chiefly "taught" by the mentor and a range of other sources (e.g., ratified books). The development of the mentee's declarative pool will then help them to become increasingly aware of different options for their coaching practice and, in conjunction, increase sensitivity to the "whys" and "why nots" of what they do. It is perhaps at this point that mentors may then deliver review blocks that highlight or reinforce the mentee's evolving beliefs on the origins, construction, and use of coaching knowledge. More specifically, such reviews could open the mentee's eyes to the point that they are now (hopefully) aware of lots more factors in the coaching process than when they started. Moreover, this awareness can then be paired with education on what the next steps towards expertise will involve (e.g., moving beyond an awareness of these multiple factors to deciding when they're more or less relevant in specific situations).

Indeed, to make the next step to multiplism, mentors may then sensibly facilitate discussion and debate where the provisional and recursive nature of coaching knowledge is emphasized (i.e., it will apply in some cases but not all and needs continual updating). For instance, a mentor may set up conversations on why a practice or session that had worked well for the mentee a few months earlier was now no longer delivering the same impact; as 
such, drawing attention away from the content and procedures of practice (e.g., were the drills set up "correctly" or not?) toward contextual factors (e.g., what progress had performers made in the intervening period? Were some performers finding the content too easy? What stage of the season was it? How much of the prior success was due to block practice? Was the assistant coach sending mixed signals?). Here, mentee learning should center on thinking and reflecting, including how they then use this "thought through" provisional knowledge in their practice. Indeed, encouraging explicit thinking allows a "cognitive apprenticeship" to be served and mental models to be developed and/or refined (Collins, Brown, \& Holum, 1991).

As mentees start to appreciate that coaching is an inherently complex and contingent process, mentors may start to include regular epistemology-oriented reviews that help mentees to reflect on their previously held beliefs on where coaching knowledge comes from, how it can change, and how it can be used. Similarly, conversations might also be held on the next step toward expertise; specifically, the ability to make appropriately balanced and evidence-based judgments. To achieve this, mentors may start to incorporate more scenariobased work. For example, discussion on multifaceted coaching challenges, which increase gradually in complexity, can be presented and options examined to identify "best fit" solutions (cf. Collins et al., 2015). Initially this will probably require the mentor to use significant probing to tease out the different options and the merits of each from the mentee. However, as the mentee's declarative understanding and professional judgment and decision making skill grows (Abraham \& Collins, 2011), and through a gradual promotion of mentee ownership, this support can then recede with the mentee responsible for conducting evidencebased, "pros and cons" trade-offs. It is at this point where Entwistle and Peterson's (2004) pivotal position would be crossed, after which meaning is sought from learning and relativism starts to become more established. In line with the expertise criteria outlined 
earlier, mentors would therefore expect to see mentees display greater independence, use their knowledge to experiment with and then develop novel solutions, manage more complex planning processes, and couch all of the above against their perceived strengths and limits. Mentees will also be more likely to critically assess their role in the wider system of which they are part, become more aware of the social pressures acting on them, and engage critically with peers and seniors (as opposed to routinely accepting their views). From here, the final mentoring phase will see the mentee view learning episodes in multiple ways and committing to a personal and reasoned perspective on what knowledge is, how it can be developed, constructed, and shared, and how it can be used to inform practice. This will inevitably align with other elements of the mentee's coaching philosophy, including the purpose of their coaching for both themselves and those they work with.

As implied in the preceding suggestions, developing sophisticated coaches therefore requires much more than just reflective practice; a pertinent point in light of the prescribed dominance of this skill in academic and applied spheres (Gordon \& Brobeck, 2010). Of course, reflective practice will still play a significant role; but as part of a holistic, systematic, and conceptually framed process. More specifically, the framework of Entwistle and Peterson (2004) and Schommer-Aikins and Easter's (2009) work on personal epistemology can be used to set what reflection is chiefly done against; in short, without such criteria against which to evaluate, reflective practice may only be elaborate navel gazing. Indeed, by encouraging mentees to deconstruct their practice against their current epistemology and, more importantly, the next stage of progression (or their zone of proximal development), they then have the chance to develop on a deeply personal and expertise-enabling level rather than reflecting at random or for the sake of reflecting alone (Grecic \& Collins, 2013; Stoszkowski \& Collins, 2014). 
While we have outlined some content of mentor support work, it is also important to stress that the features described above have implications for the nature of the mentor-mentee relationship. Given the challenging path ahead, including anticipated dips in confidence and performance, mutual trust will be pivotal (Bloom et al., 1998). As such, while partnerships will usually be set up through formal system requirements (i.e., as part of coach education programs), mentors clearly need to possess the interpersonal skills that can foster immediate (and enduring) rapport and respect. Indeed, first impressions may make or break (or at least significantly delay or impinge on) the mentor-mentee relationship, particularly with naïve mentees and those fearful of being exposed or undermined. As part of this process, and as touched upon earlier, mentors would do well to set clear expectations over each partner's role and the program of support. Indeed, it might often be the case that mentees, through socialization and experience of drill-focused qualifications, expect the mentor to simply provide the answers to their coaching needs. As also mentioned earlier, mentors may sensibly fulfill this role through the provision of coaching drills and "do it like this" guidance at the beginning of the relationship. After this "buy in" period, however, mentors will need to progressively weaken dependence and increase mentee ownership; as such, moving from instructor to educator to collaborator to consultant to one of several sounding boards (cf. Raelin, 2007; Grecic \& Collins 2012). Importantly, this process will also depend upon the appropriate deployment of less socially desirable skills; namely, the ability to directly and indirectly challenge mentees on why they are doing what they are doing (cf. Nash, 2003). Finally, for mentees struggling to manage the complex links between theory, critical thinking, and practice, mentors would also seem well advised to have skills that help individuals cope with uncertainty. Specifically, mentors should help mentees to challenge the assumptions behind their struggle, seek further information to make more informed decisions, debate between options rather than falling back on biases and heuristics, and identify future 
contingencies (Kahneman \& Klein, 2009) so that complexity is adapted to and not absorbed (Theodoridis \& Bennison, 2009).

\section{Meso-Level Action: Communities of Practice}

Building on the features of one-on-one mentoring, encouraging mentees to participate in targeted communities of practice (herafter CoPs) may also work to systematically expose these coaches to different views and then onto critical and evidence-based discussion of these views. Indeed, the chance to engage with larger pools of knowledge, share ideas, and probe the rationale behind these ideas can enable the mentee to extend their declarative knowledge base as well as what they can do with this knowledge, who with, when, where, how, and why. By strategically selecting the CoP based on the aims and current epistemological positions of its members, such groups can also serve a social support purpose as mentees start to question their practice and face the unnerving world of multiplism and relativism. Indeed, many will feel uneasy with opening up on why they do what they do (or not being able to explain why they do what they do); particularly those who (a) are focused on rapid upward mobility (via impression management), (b) fear being exposed in front of their peers or role models, (c) are particularly staunch dualists, (d) are easily impressionable (i.e., "if X says so then it must be true!"), or (e) some combination of all four. In this way, mentors will have to play a critical role in CoPs to ensure a shared purpose, a critical but non-judgmental culture, and benefit for all members. Again, the mentor will likely assume a neutral position; not that of an assessor but, returning to Vygotsky, a "more capable other" who can appropriately manipulate social environments (Potrac \& Cassidy, 2006).

Early on, it would seem sensible that the mentor leads the agenda for the more formal aspects of interaction, such as group meetings, before gradually progressing toward the more consultant-type role noted previously. Guidance on how mentees engage with more informal features, such as social media, blogs, and other online resources would also seem wise in an 
opinion-dense world (Stokowski, 2012); in effect, shaping the lens by which mentees collect, interpret, and reflect on (apparently) relevant information. Finally, another useful approach might see mentors operate "buddy systems" whereby a mentee is paired with a more capable peer; or, more specifically, a coach who is one step closer to relativism than themselves. In this way, the thinking and behavior desired of the mentee can be modeled by this individual, who can also provide a vital source of confidence during what may be uncertain times (i.e., "if they can do it then so can I"; Bandura, 1977).

\section{Macro-Level Action: Formal Coach Education}

Ultimately, the full extent to which mentors can support the development of creative, forward-thinking, and adaptable coaches will be shaped by the messages sent by those higher up their sport system's food chain; especially via formal coach education. Following points made in our Introduction, formal coach education has traditionally adopted a procedural (i.e., technique/drill-oriented) approach to the development of coaches rather than encouraging an appropriate expansion of declarative knowledge (i.e., the "whys, why nots, and what would have to be differents"). As such, sport education systems have often, whether knowingly or unknowingly, worked to a dualist and reductionist model; as driven by the desire to identify clear competencies on which effective coaching can be assessed and reproduced (particularly at the novice end of the coaching spectrum). It is not until coaches reach the higher levels of education that they are then normally expected to develop and demonstrate the core problem solving and decision making skills that more closely characterize expertise (albeit still with a technical/drill orientation). This overall approach is conveyed in Figure 2a. However, as the development of expertise and a relativist epistemology is a protracted and demanding process, only those who have been highly self-driven in their acquisition of knowledge, critical reflection, and learning/debating with more capable others will tend to go on to deliver expert practice (as defined in this paper) once the top award has been achieved. 
So how can sports address the contradiction of pushing for more creative, forwardthinking, and adaptable coaches - as supported by mentoring programs - yet achieve this with dualist/competency-oriented courses? Although this is clearly a major and multifaceted challenge, a model of formal education that more closely reflects that shown in Figure $2 b$ would seem to offer a better fit than the often drill/technique-dominated courses currently delivered by many sports. Importantly, such an approach would clearly define expertise from the off, then set the tone for development by encouraging coaches to continuously engage with and build their declarative understanding as they progress through every level. In this manner, formal courses could then align with the rewiring activities of mentors (and viceversa) and help coaches to: (a) increasingly deepen their understanding of what expertise is and what it's not; and (b) build their own bespoke, contextualized, and "declarative-rich" knowledge (i.e., knowledge that allows them to take resources and apply them in a way that delivers peak impact in their environment for their purposes). Moreover, by awarding qualifications to those displaying suitable epistemological development (i.e., transitioning from a "black and white" to a "shades of grey" approach) social expectations can then also be shaped to promote the need for an extensive declarative knowledge. Indeed, this strategy would send a strong message, especially when reinforced by coach mentors, that understanding the "whys" and "why nots" of coaching is both an essential and normal feature of becoming a better coach.

\section{Concluding Comments}

In light of the recent push on mentoring as a means to develop more creative, forward-thinking, and adaptive coaches - as well as coach preferences for mentoring support (Cushion 2006) - this paper has attempted to identify important features, relevant theory, and potential mechanisms for the development of expert coaches (or at least coaches who are closer to this level). More specifically, we have critically explored the role of mentoring in 
coach development, the nature of the mentor-mentee relationship, and, most importantly, how mentee expertise may effectively developed through complementary action at the micro (i.e., one-on-one mentoring), meso (i.e., communities of practice), and macro (i.e., formal coach education) level. In doing so, we have promoted a focus on personal epistemology for mentors, mentees, and the wider sport system alike. We also hope that this discussion will help coach educators and researchers to further evaluate and improve mentoring programs. Indeed, as well as examining the relevance and utility of our main suggestions on the theory and mechanisms of epistemological development, we expect additional benefits to come from work that explores areas including: the relationship being established between mentors and mentees; the extent to which mentors fully understand how expert coaching can be achieved; the expectations of mentees over what expert coaching is and how it can be reached; and the identification of sport-specific tactics and tools for use at each phase of epistemological development. Similarly, but more broadly, we also hope that our work helps coach educators and researchers to investigate the parameters of expertise that are currently being endorsed at different levels of coaching qualifications, as well as the implications that these have on those entering and making their way through the pathway. 


\section{References}

Abraham, A., \& Collins, D. (1998). Examining and extending research in coach development. Quest, 50, 59-79.

Abraham, A., \& Collins, D. (2011). Taking the next step: Ways forward for coaching science. Quest, 63, 366-384.

Abraham, A., Collins, D., \& Martindale, R. (2006). The coaching schematic: Validating through expert coach consensus. Journal of Sports Science, 24, 549-564.

Bandura, A. (1977). Self efficacy: Toward a unifying theory of behavioural change. Psychological Review, 84, 191-215.

Bloom, G. A., Durrand-Bush, N., Schinke, R. J., \& Salmela, J. H. (1998). The importance of mentoring in the development of coaching and athletes. International Journal of Sport Psychology, 29, 267-281.

Cassidy, T., Jones, R., \& Potrac, P. (2004). Understading sports coaching. London: Routledge.

Collins, D., Abraham, A., \& Collins, R. (2012). On vampires and wolves: exposing and exploring reasons for the differential impact of coach education. International Journal of Sports Psychology, 43, 255-271.

Collins, A., Brown, S. J., \& Holum, A. (1991). Cognitive apprentiship: Making thinking visible. American Educator, 6, 38-46.

Collins, D., Burke, V., Martindale, A., \& Cruickshank, A. (2015). The illusion of competency versus the desirabilty of expertise: Seeking a common standard for support professions in sport. Sports Medicine, 45, 1-7.

Cushion, C. (2006). Mentoring: Harnessing the power of experience. In R. L. Jones (Ed.), The Sports Coach as Educator: Re-conceptulising sports coaching (pp. 128-144). Oxon: Routledge. 
Cushion, C. J. (2010). Coach behaviour. In J. Lyle (Ed.), Sports coaching: professionalisation and ractice (pp. 43-62). London: Elsevier.

Cushion, C. J., Armour, K. M., \& Jones, R. L. (2003). Coach education and continuing professional development: Experience and learning to coach. National Assoicaition for Physical Education in Higher Education, 55, 215-230.

Entwistle, N. J., \& Peterson, E. R. (2004). Conceptions of learning and knowledge in higher education: Relationship with study behaviour and influences of learning environments. International Journal of Educational Research, 41, 407-428.

Giacobbi, P. R., Poczwardowski, A., \& Hager, P. (2005). A pragmatic research philosophy for sport and exercise psychology. The Sport Psychologist, 19, 18-31.

Gordon, S. P., \& Brobeck, S. R. (2010). Coaching the mentor: Facilitating reflection and change. Mentoring \& Tutoring: Partnership in Learning, 18, 427-447.

Grecic, D., \& Collins, D. (2013). The epistemological chain: Practical applications in sports. Quest, 65, 151-168.

Jones, R. L., Harris, R., \& Miles, A. (2009). Mentoring in sports coaching: A review of the literature. Physical Education and Sport Pedagogy, 14, 267-284.

Kahneman, D., \& Klein, G. (2009). Conditions for intuitive expertise: A failure to disagree. American Psychologist, 64, 515-526.

MacNamara, Á., \& Collins, D. (2015). Twitterati and Paperati - evidence versus popular opinion in science communication. British Journal of Sports Medicine. Advance online publication. 10.1136/bjsports-2015-094884

Nash, C. (2003). Development of a mentoring system within coaching practice. Journal of Hospitality, Leisure, Sport and Tourism Education, 2, 39-47.

Nash, C., Martindale, R., Collins, D., \& Martindale, A. (2012). Parameterising expertise in coaching: Past, present and future. Journal of Sports Sciences, 30, 985-994. 
Nash, C. S., Sproule, J., \& Horton, P. (2008). Sports coaches' perceived role frames and philosophies. International Journal of Sports Science and Coaching, 3, 539-554.

Nelson, L., Cushion, C., \& Potrac , P. (2013). Enhancing the provision of coach education: The recommendations of UK coaching practitioners. Physical Education and Sport Pedagogy, 18, 204-218.

Nussbaum, E. M., \& Bendixen, L. D. (2003). Approaching and avoiding arguments: The role of epistemological beliefs, need for cognition and extraverted personality trait. Contemporary Educational Psychology, 28, 573-595.

Martindale, A., \& Collins, D. (2005). Professional judgment and decision making: The role of intention for impact. The Sport Psychologist, 19, 303-317.

Parsloe, E., \& Wray, M. (2000). Coaching and mentoring: Practical methods to improve learning. London: Kogan-Page.

Perry, W. (1981). Cogntive and ethical growth: The making of meaning. In A. Chickering (Ed.), The Modern American College (pp. 76-116). San Francisco: Jossey-Bass.

Potrac, P., \& Cassidy, T. (2006). The coach as a " more capable other". In R. L. Jones (Ed.), The sports coach as educator: Re-conceptulising sports coaching (pp. 39-50). Oxon: Routledge.

Raelin, J. A. (2007). Toward an epistimology of practice. Academy of Management Learning \& Education, 6, 495-519.

Roberts, A. (2000). Mentoring revisited: A phenomological reading of literature. Mentoring \& Tutoring: Partnership in Learning, 8, 145-170.

Schempp, P. G., McCullick, B. A., Busch, C. A., Webster, C., \& Mason, I. S. (1983). The self-monitoring of expert sport instructors. International Journal of Sports Science \& Coaching, 1, 25-35. 
Schommer-Aikins, M., Brookhart, S., Hutter, R., \& Wei Cheng, M. (2000). Understanding middle students' beliefs about knowledge and learning using a multidimensional paradigm. The Journal of Educational Research, 94, 120-127.

Schommer-Aikins, M., \& Easter, M. (2009). Ways of knowing and willingness to argue. The Journal of Psychology, 143, 117-132.

Schommer-Aikins, M., \& Hutter, R. (2002). Epistemological beliefs and thinking about everyday controversial issues. The Journal of Psychology, 136, 5-20.

Stoszkowski, J., \& Collins, D. (2014). Communities of practice, social learning and networks: Exploiting the social side of coach development. Sport, Education and Society, 19, 773-788.

Tetlock, P. (2005). Expert political judgement: How good is it? How can we know. Princeton: University Press.

Theodoridis, A., \& Bennison, D. (2009). Complexity theory and retail location strategy. The International Review of Retail, Distribution and Consumer Research, 19, 389-403.

Vygotsky, L. S. (1978). Mind in society: The development of higher psychological proceesses. Cambridge: Harvard University Press.

Wernthner, P., \& Trudel, P. (2006). A new theoretical perspective for understanding how coaches learn to coach. The Sport Psychologist, 20, 198-212.

Wiman, M., Salmoni, A. W., \& Hall, C. R. (2010). An examination of the definition and development of expert coaching. International Journal of Coaching Science, 4, 37-60. 
Figure 1. Progressions of knowledge use and conceptions of learning (adapted from Entwistle \& Peterson, 2004).

\section{Conceptions of knowledge}

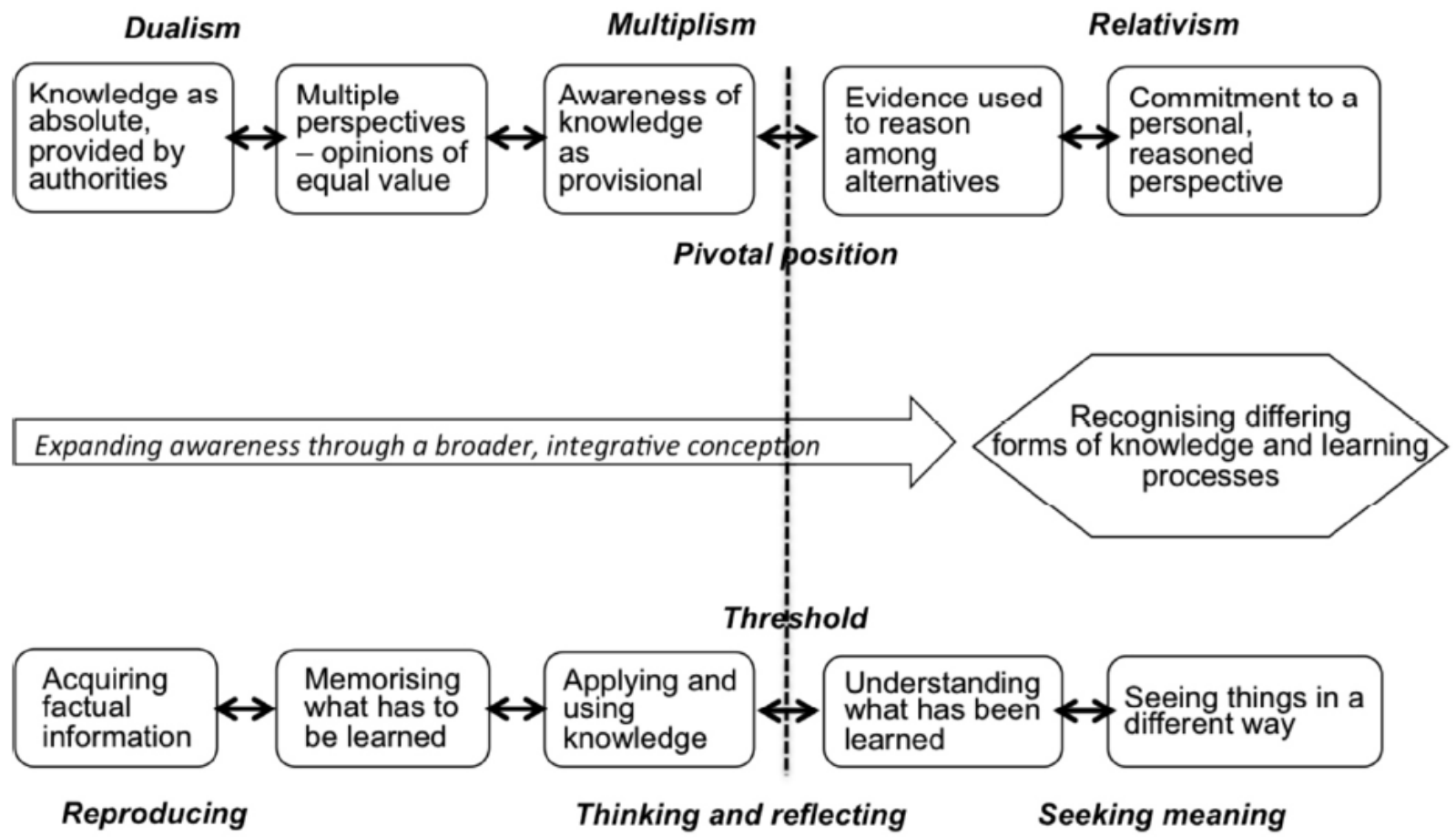

Conceptions of learning 
Figure $2 a$. Knowledge and assessment orientation of typical current formal coach education programs.

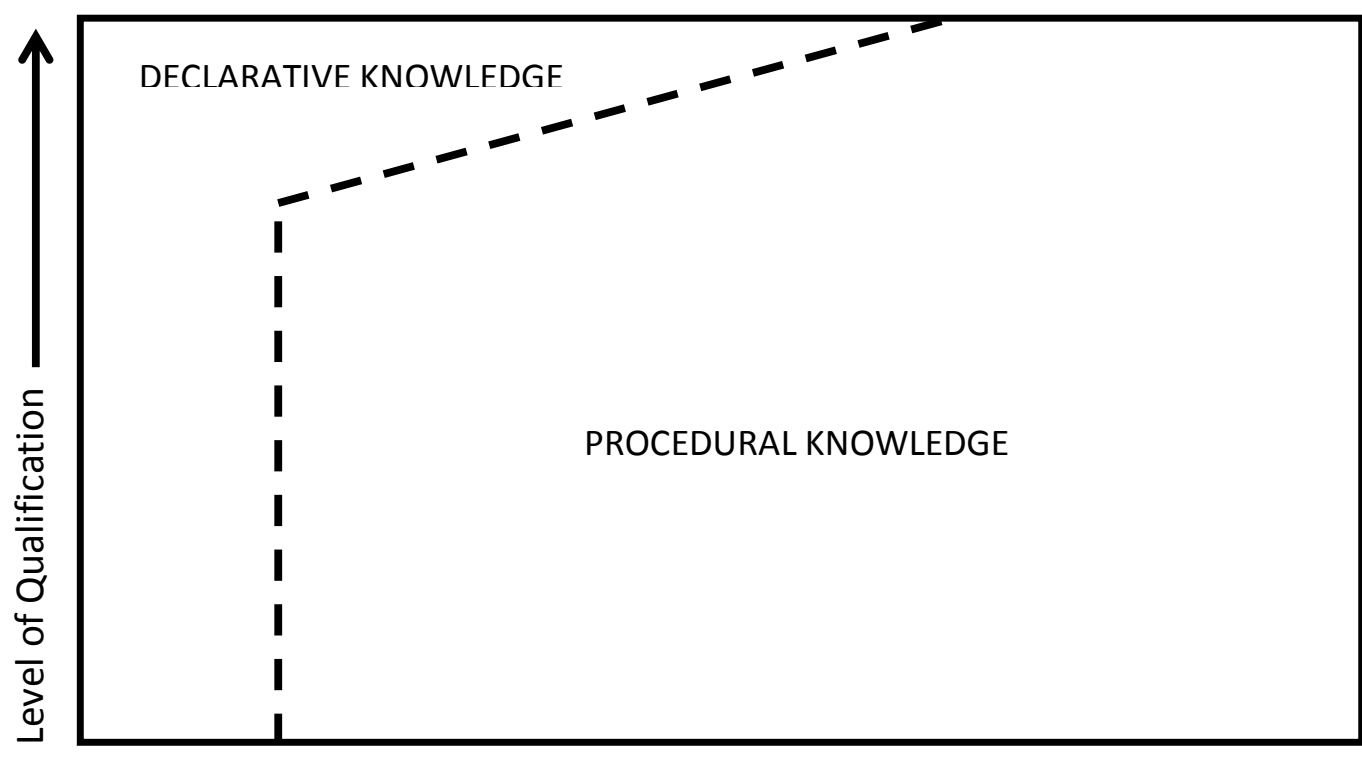

Knowledge/Assessment Focus 
Figure $2 b$. Knowledge and assessment orientation of more expertise-enabling formal coach education programs.

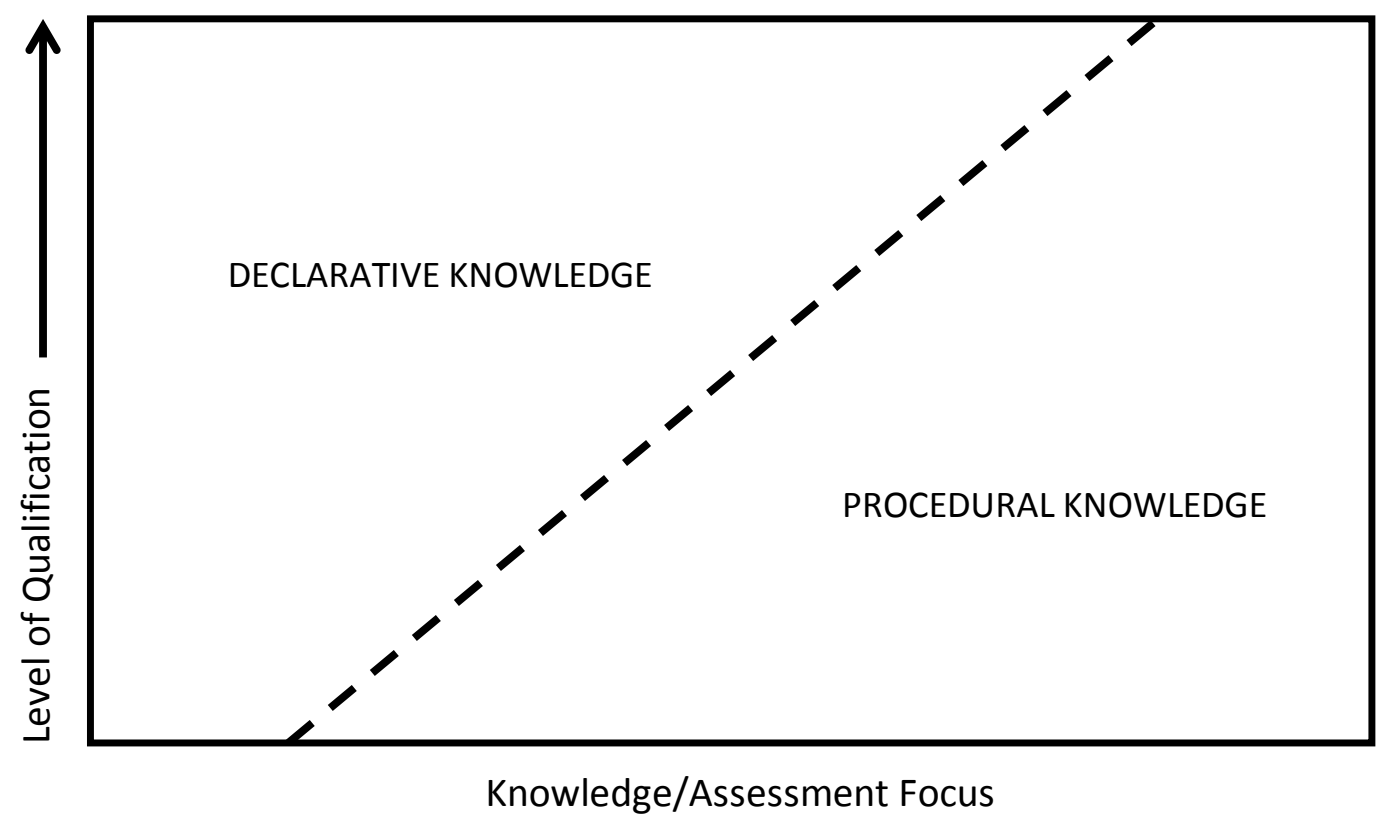

